\title{
Role of microRNA-21 in radiosensitivity in non-small cell lung cancer cells by targeting PDCD4 gene
}

\author{
Li-Peng Jiang ${ }^{1}$, Chun-Yan He ${ }^{2}$, Zhi-Tu Zhu ${ }^{3}$ \\ ${ }^{1}$ Department of Radiation Oncology, First Affiliated Hospital of Liaoning Medical University, Jinzhou 121000, P.R. China \\ ${ }^{2}$ Department of Prosthodontics, Second Affiliated Hospital of Liaoning Medical University, Jinzhou 121000, P.R. China \\ ${ }^{3}$ Department of Oncology, First Affiliated Hospital of Liaoning Medical University, Jinzhou 121000, P.R. China \\ Correspondence to: Zhi-Tu Zhu, email: ZHUzhitu_806@163.com
}

Keywords: microRNA-21, PDCD4, non-small cell lung cancer, radiotherapy, PI3K

Received: April 09, $2016 \quad$ Accepted: December 26, $2016 \quad$ Published: February 23, 2017

\section{ABSTRACT}

This study aims to explore the effects of microRNA-21 (miR-21) on radiosensitivity in non-small cell lung cancer (NSCLC) by targeting programmed cell deanth 4 (PDCD4) and regulating PI3K/AKT/mTOR signaling pathway. Cancer tissues and adjacent normal tissues were collected from 97 NSCLC patients who received a standard radiotherapy regimen. TUNEL assay was applied to determine cell apoptosis in tissues. The qRT-PCR assay was used to detect the expressions of miR-21 expression and PDCD4 mRNA. The protein expressions of PDCD4 and PI3K/ AKT/mTOR signaling pathway-related proteins were determined by Western blotting. Colony formation assay was used to observe the sensitivity to radiotherapy of NSCLC cells. Flow cytometry was adopted to testify cell apoptosis. Compared with adjacent normal tissues, miR-21 expression was significantly increased and the mRNA and protein expressions of PDCD4 were decreased in NSCLC tissues. Higher miR-21 expression was associated with attenuated radiation efficacy and shorter median survival time. PDCD4 was the target gene of miR-21. The miR-21 mimics and siRNAPDCD4 decreased the sensitivity to radiotherapy and cell apoptosis of A549 and H1299 cells and activated PI3K/AKT/mTOR pathway. The sensitivity of A549 and H1299 cells was strengthened in the miR-21 inhibitors group and the PI3K/AKT/mTOR inhibitors group. The siRNA-PDCD4 could reverse the effects of miR-21 inhibitors on sensitivity to radiotherapy and cell apoptosis of NSCLC cells. Our findings provide strong evidence that miR-21 could inhibit PDCD4 expression and activate PI3K/AKT/mTOR signaling pathway, thereby affecting the radiation sensitivity of NSCLC cells.

\section{INTRODUCTION}

Non-small cell lung cancer (NSCLC) accounts for about $85 \%$ of all lung cancer cases, which also include adenocarcinoma, large cell carcinoma, and squamous cell carcinoma [1]. Five-year survival rates can reach $20-30 \%$ in NSCLC patients after surgery [2]. Generally, elderly people are more likely to develop lung cancer than younger people, and males are at higher risk than that of females [3]. The main risk factor for NSCLC is smoking, to which $80 \%$ of lung cancer cases in males can be attributed [4]; other factors, such as occupational and environmental exposures, ionizing radiation, and genetic causes are also well-known risk factors for NSCLC [5]. At present, therapies for NSCLC include surgery, chemotherapy, and radiotherapy, and can be applied independently or jointly according to the range and progression of the disease [6]. Local and distant metastasis is a common clinical problem during the treatment of lung cancer, and is the primary contributor to poor prognosis in many patients [7]. Gene therapies for lung cancer, some of which have entered clinical trials, have developed rapidly in recent years [8]. Increasing the use of therapies that target and regulate gene expression and related molecular markers may improve NSCLC therapy [9].

MicroRNAs (miRs) are a recently discovered class of non-coding small RNA molecules approximately 22 nucleotides in length that play important roles in cell differentiation, proliferation, apoptosis, and metabolism by inhibiting target genes [10]. The miR-21 is up-regulated in 
multiple solid tumors, including lung cancer, breast cancer, and pancreatic cancer, and is overexpressed in most cancer tissues, suggesting a close relationship between miR-21 expression and tumor development [11]. Differences in miR expression are related to the efficacy of radiotherapy in NSCLC, and miRs may therefore serve as biomarkers for predicting the efficacy of radiotherapy [12]. For instance, miR-25 was reported to directly regulate B-cell translocation gene 2 expressions, leading to modulation on sensitivity of radiotherapy in NSCLC cells [13]. Human programmed cell death 4 (PDCD4) gene was mapped in chromosome 10q24, but its function has not been well defined [14]. MiR-21 regulates the expression of PDCD4 mRNA and protein, and thus reduces the sensitivity of lung cancer to radiotherapy $[15,16]$. The PDCD4 gene, which is frequently expressed in normal tissues and functions by affecting gene translation and transcription, was initially discovered for its role in cell apoptosis [17]. In addition, a previous study reported that miR-21 is highly expressed in patients with NSCLC and inhibition of miR-21 expression reduces proliferation, migration, and invasion of A549 cells by up-regulating PDCD4 expression [18]. Therefore, we hypothesized that the regulation of miR-21 in PDCD4 gene may relate to the sensitivity of radiotherapy in NSCLC.

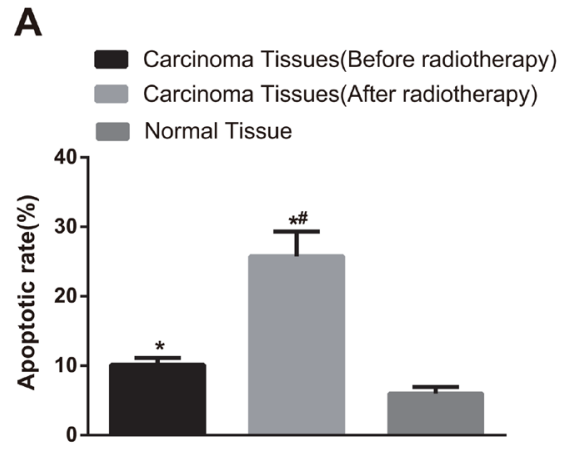

C

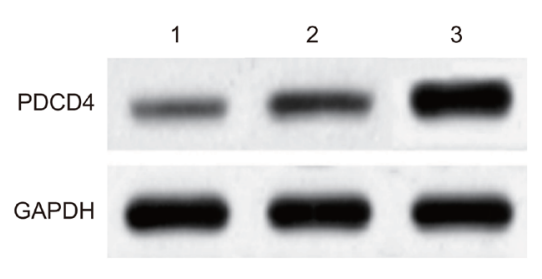

Furthermore, phosphatidylinositol-3-kinase/protein kinase $\mathrm{B} /$ mammalian target of Rapamycin (PI3K/AKT/mTOR) pathway was reported to implicate in cell survival, proliferation and angiogenesis [19]. And the therapeutic potential of combination strategy for mTOR inhibitors with conventional chemotherapy in anti-microtubule agents, other molecular targeting agents, as well as radiotherapy was highlighted in hepatocellular carcinoma [20]. In this regards, the possible role of PI3K/AKT/ mTOR signaling pathway is also investigated to explore the possible mechanism of sensitivity of radiotherapy in NSCLC. Therefore, we explore the effects of miR-21 on sensitivity to radiotherapy in NSCLC by targeting PDCD4 and regulating $\mathrm{PI} 3 \mathrm{~K} / \mathrm{AKT} / \mathrm{mTOR}$ signaling pathway.

\section{RESULTS}

\section{Comparisons of cell apoptosis and miR-21 expression and $P D C D 4$ mRNA expression in NSCLC tissues and adjacent normal tissues before and after radiotherapy}

As shown in Figure 1A, compared with adjacent normal tissues, the apoptotic index (AI) values of
B

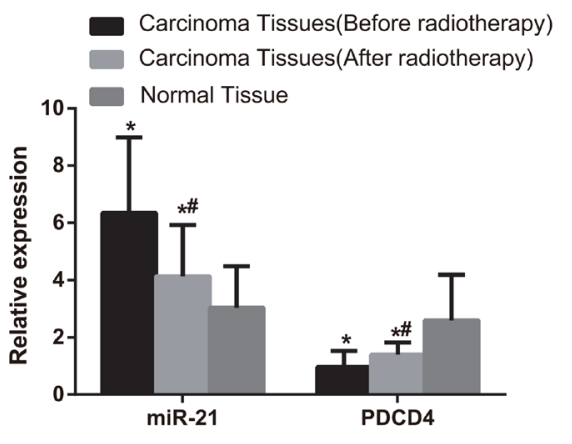

D

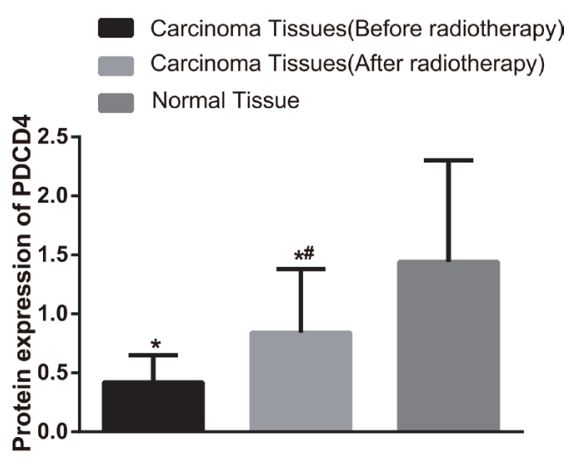

Figure 1: Comparisons of cell apoptosis and the miR-21 expression, PDCD4 mRNA and protein expressions in NSCLC and adjacent normal tissues before and after radiotherapy. Note: A. Comparisons of apoptotic index between NSCLC tissues and adjacent normal tissues before and after radiotherapy; B. Comparisons of the miR-21 expression and PDCD4 mRNA expression between NSCLC tissues and adjacent normal tissues before and after radiotherapy; C. The protein expression of PDCD4 detected by Western blotting; 1, NSCLC tissues (before radiotherapy); 2, NSCLC tissues (after radiotherapy); 3, adjacent normal tissues (before radiotherapy); D. Comparisons of the PDCD4 protein expression between NSCLC tissues and adjacent normal tissues before and after radiotherapy; *, compared with adjacent normal tissues, $P<0.05$; \#, compared with those before radiotherapy, $P<0.05$; NSCLC, non-small cell lung cancer; PDCD4, programmed cell death 4; GAPDH, glyceraldehyde-3-phosphate dehydrogenase; miR-21, microRNA-21. 
Table 1: Correlations the miR-21 expression, PDCD4 mRNA and protein expression with sensitivity to radiotherapy of NSCLC patients

\begin{tabular}{llccc}
\hline Group & $\mathbf{N}$ & miR-21 & PDCD4 mRNA & PDCD4 Protein \\
\hline CR & 14 & $3.32 \pm 1.29$ & $1.65 \pm 0.53$ & $1.19 \pm 0.72$ \\
PR & 44 & $3.63 \pm 1.36$ & $1.59 \pm 0.24$ & $1.07 \pm 0.34$ \\
SD & 23 & $4.74 \pm 2.17^{* \#}$ & $1.27 \pm 0.19$ & $0.47 \pm 0.50^{* \#}$ \\
PD & 16 & $5.42 \pm 1.76^{* \#}$ & $1.25 \pm 0.15$ & $0.44 \pm 0.28^{* \#}$ \\
\hline
\end{tabular}

Note: miR-21, microRNA-21; PDCD4, programmed cell death 4; NSCLC, non-small cell lung cancer; CR, complete remission; PR, partial remission; $\mathrm{SD}$, stable disease; $\mathrm{PD}$, progressive disease;" indicates when comparing with the ineffective group, $P<0.05$; ${ }^{*}$ indicates when comparing with the ineffective group, $P<0.05$.

NSCLC tissues were significantly elevated before and after radiotherapy $(P<0.001)$. In NSCLC tissues, the AI value after radiotherapy was higher than that before radiotherapy $(P<0.001)$. The miR-21 expression in NSCLC tissues before and after radiotherapy (before, $6.35 \pm 2.64$; after, $4.14 \pm 1.79)$ was higher than that in adjacent normal tissues (3.04 \pm 1.45$)$ (Figure 1B, both $P<0.05)$. In contrast, $P D C D 4$ mRNA expression in NSCLC tissues before and after radiotherapy (before, $0.96 \pm 0.57$; after, $1.47 \pm 0.32$ ) was lower than that in adjacent normal tissues $(2.60 \pm 1.59)$ (both $P<0.05)$. The miR-21 expression in NSCLC tissues after radiotherapy was remarkably decreased compared with that before radiotherapy, while PDCD4 mRNA expression in NSCLC tissues after radiotherapy was elevated in comparison with that before radiotherapy (both $P<0.05$ ). PDCD4 protein expression in NSCLC tissues before and after radiotherapy (before, $0.42 \pm 0.23$; after, $0.84 \pm 0.54$ ) was lower than that in adjacent normal tissues $(1.44 \pm 0.86)$ (Figure $1 \mathrm{C} \&$ 1D, both $P<0.05)$. PDCD4 protein expression in NSCLC tissues after radiotherapy was elevated in comparison with that before radiotherapy (both $P<0.05$ ).

\section{Correlations of miR-21 expression and PDCD4 mRNA and protein expressions with radiotherapy efficacy of NSCLC patients}

After radiotherapy, there were 14 cases of complete remission (CR), 44 cases of partial remission (PR), 23 cases of stable disease (SD), and 16 cases of progressive disease (PD). The effective rate (CR + PR) was $59.8 \%$. As shown in Table 1 , no significant difference was revealed concerning miR-21 expression and mRNA and protein expressions of PDCD4 between the $\mathrm{CR}$ group and the PR group and between the SD group and the PD group (both $P>0.05$ ). The $\mathrm{CR}$ and $\mathrm{PR}$ groups exhibited lower miR-21 expression and higher mRNA and protein expressions of PDCD4 than those in the SD and PD groups (all $P<0.05$ ).

\section{Effects of miR-21 on long-term efficacy of patients after radiotherapy}

Patients were classified into the low miR-21 expression group $(\mathrm{miR}-21 \leq 4.23)$ and the high miR-21 expression group (miR-21 > 4.23). In the high miR-21 expression group, 4 patients died among the 43 cases $(4 / 43,9.30 \%)$ with a median progression free survival (PFS) of 15 months. In the low miR-21 expression group, 2 contacts were lost among the 54 cases $(2 / 54$, $3.70 \%$ ) with a PFS of 24 months. The PFS Kaplan-Meier curve of the two groups was drawn in Figure 2. By logrank test, the PFS of the high miR-21 expression group was reduced compared to the low miR-21 expression group $(P<0.05)$. The univariate analysis revealed that no statistical difference was found in terms of age, gender, and smoking history on the effects of longterm efficacy (Table 2, $P>0.05$ ), whereas, tumor-nodemetastasis (TNM) stage and lymph node metastasis were significantly associated with long-term efficacy $(P<0.05)$.

\section{Comparisons of the miR-21 expression, PDCD4 mRNA and protein expressions in each group after cell transfection}

In A549 cells, compared with the blank group and the $\mathrm{NC}$ group, miR-21 expression in the miR-21 mimics group was evidently increased, while significantly decreased in the miR-21 inhibitors and miR-21 inhibitors + si-PDCD4 groups (Figure 3A, all $P<0.05$ ). There was no significant difference in miR-21 expression in the siPDCD4 group and the PI3K/AKT/mTOR inhibitors group in contrast to the blank and $\mathrm{NC}$ groups (all $P>0.05$ ). In comparisons to the blank and NC groups, PDCD4 mRNA and protein expressions were decreased in both the miR21 mimics and si-PDCD4 groups, but increased in the miR-21 inhibitors group (Figure 3B \& 3D, all $P<0.05$ ). There was no significant difference in PDCD4 mRNA and 
protein expressions in the PI3K/AKT/mTOR inhibitors group compared to the blank and NC groups (all $P>0.05$ ). PDCD4 mRNA and protein expressions were inhibited in the miR-21 inhibitors + si-PDCD group in comparison to the miR-21 inhibitors group $(P<0.05)$. The observations in H1299 cells were similar with that in A549 cells (Figure 4). The miR-21 expression was negatively associated with PDCD4 mRNA expressions and overexpression of miR21 was able to suppress PDCD4 expression (Figure 3E \& 4E).

\section{Targeting relationship between miR-21 and PDCD4}

Using the TargetScan database as a reference, PDCD4 was identified as a potential target gene of miR21 (Figure 5A). Dual luciferase reporter gene assays were used to confirm this result. The luciferase signal in cells transfected with both miR-21 and PDCD4-3'UTR decreased by about $49 \%$ as compared to the other groups (Figure 5B, all $P<0.05$ ). Luciferase signals did not decrease in any of the groups transfected with PDCD4 mut-3'-UTR mutants (all $P>0.05$ ). These results indicated that miR-21 binds to the 3' UTR region of $P D C D 4$, inhibiting its transcription and thus regulating its expression. PDCD4 therefore was likely a direct target gene of miR-21.

\section{Comparisons of the expressions of PI3K/AKT/ mTOR signaling pathway-related proteins in each group after radiotherapy}

As shown in Figure 6, there were no significantly differences in expressions of AKT and mTOR among all the transfected groups in both A549 and H1299 cells (all $P>0.05)$. No significant difference was found regarding expressions of PI3K, p-AKT and p-mTOR between the blank group and the $\mathrm{NC}$ group (all $P>0.05$ ). Compared with the blank group, the expressions of PI3K, p-AKT and p-mTOR were remarkably increased in both the miR-21 mimics group and the si-PDCD4 group, but decreased in the miR-21 inhibitors group and the PI3K/AKT/mTOR inhibitors group (all $P<0.05$ ). The miR-21 inhibitors group had relative lower expressions of PI3K, p-AKT and $\mathrm{p}-\mathrm{mTOR}$ in comparison to the miR-21 inhibitors + siPDCD4 group (all $P<0.05$ ). Those results suggested that miR-21 inhibitors could suppress the activation of PI3K/ AKT/mTOR signaling pathway and si-PDCD4 could reverse this suppression.

\section{Effect of miR-21 on radiosensitivity of NSCLC cells in each group}

The results for colony formation assay were presented in Figure 7. There were no significant

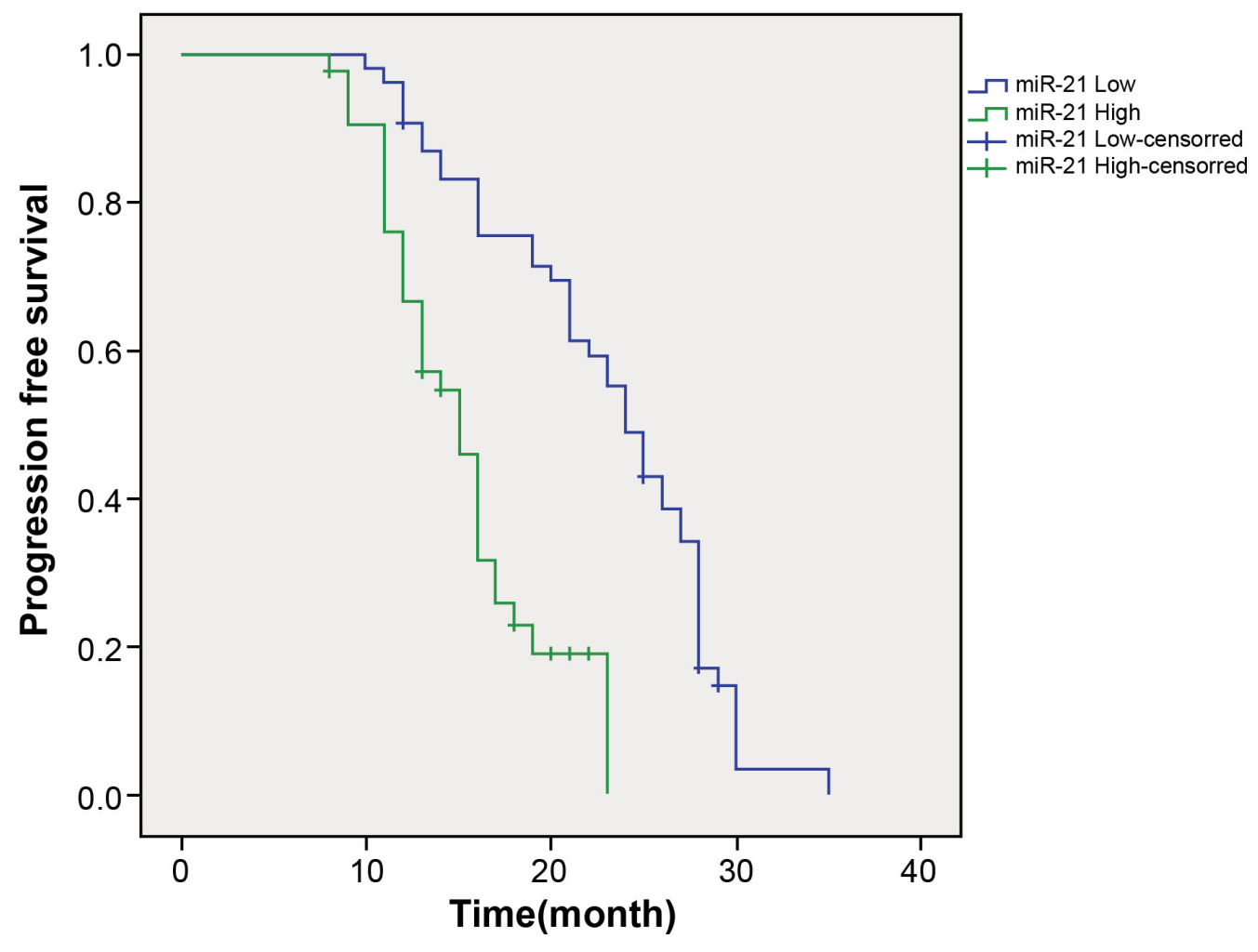

Figure 2: Comparison of progression free survival between the low miR-21 expression group and the high miR-21 expression group. Note: miR-21, microRNA-21. 
Table 2: Univariate analysis of median progression free survival of the high miR-21 expression group and the low miR-21 expression group

\begin{tabular}{|c|c|c|c|}
\hline Variable & $\begin{array}{c}\text { Low miR-21 expression } \\
\text { group }\end{array}$ & $\begin{array}{l}\text { High miR-21 expression } \\
\text { group }\end{array}$ & $P$ \\
\hline \multicolumn{4}{|l|}{ Age (years) } \\
\hline$\geq 60$ & 32 & 28 & 0.555 \\
\hline$<60$ & 22 & 15 & \\
\hline \multicolumn{4}{|l|}{ Gender } \\
\hline Male & 30 & 26 & 0.627 \\
\hline Female & 24 & 17 & \\
\hline \multicolumn{4}{|c|}{ Smoking history } \\
\hline Yes & 41 & 37 & 0.304 \\
\hline No & 13 & 6 & \\
\hline \multicolumn{4}{|c|}{ Lymph node metastasis } \\
\hline Yes & 35 & 37 & 0.018 \\
\hline No & 19 & 6 & \\
\hline \multicolumn{4}{|l|}{ TNM stage } \\
\hline I stage & 11 & 2 & 0.030 \\
\hline II stage & 15 & 12 & \\
\hline III stage & 15 & 9 & \\
\hline IV stage & 13 & 20 & \\
\hline
\end{tabular}

Note: TNM, tumor-node-metastasis; miR-21, microRNA-21.

differences in survival fraction (SF) of H1299 and A549 cells in the blank and $\mathrm{NC}$ groups at 0 Gy, 2 Gy and 4 Gy (all $P>0.05$ ). The $\mathrm{SF}$ in the miR-21 mimics group and the si-PDCD4 group were decreased compared with the blank group and the NC group (all $P<0.05$ ) in a dosagedependent manner. The SF in the miR-21 inhibitors group and the PI3K/AKT/mTOR inhibitors group were lower in comparison with the blank and $\mathrm{NC}$ groups in a dosage-dependent manner (all $P<0.05$ ). Compared with the miR-21 inhibitors group, the SF in the miR-21 inhibitors + si-PDCD4 group was elevated $(P<0.05)$. Those results suggested that miR-21 inhibitors could enhance the radiosensitivity in A549 and H1299 cells, but the application of si-PDCD4 could reverse the decreased radiosensitivity induced by miR-21 inhibitors.

\section{Comparisons of cell apoptosis of NSCLC cells in each group after radiotherapy}

As showed in Figure 8, there was no significant difference in apoptosis rate between the NC group and the blank group in A549 cells. In comparisons with the blank group, the apoptosis rate in both the miR-21 mimics group and the si-PDCD4 group was decreased, while the apoptosis rate in the miR-21 inhibitors group and the PI3K/AKT/mTOR inhibitors group was increased (all $P$ $<0.05)$. The miR-21 inhibitors + si-PDCD4 group had relative lower apoptosis rate compared with the miR-21 inhibitors group $(P<0.05)$. The observations in A549 cells were the same with those in H1299 cells (Figure 9). Above results showed that miR-21 inhibitors could elevate the apoptosis rate in both A549 and H1299 cells, while si-PDCD4 could decrease the promotion of apoptosis induced by miR-21 inhibitors.

\section{DISCUSSION}

High miR-21 expression and low PDCD4 mRNA expression in NSCLC tissues correlate strongly with disease occurrence, invasion, and metastasis, and therefore predict poor prognosis in NSCLC patients [21]. Additionally, upregulation of PDCD4 and downregulation of miR-21 inhibits NSCLC proliferation and migration [18]. Here, we explore the specific mechanisms by which miR-21 regulates the expression of PDCD4 and subsequently affects the efficacy of radiotherapy in NSCLC. Our results may facilitate clinical diagnosis and prognosis evaluation for NSCLC patients. 
A
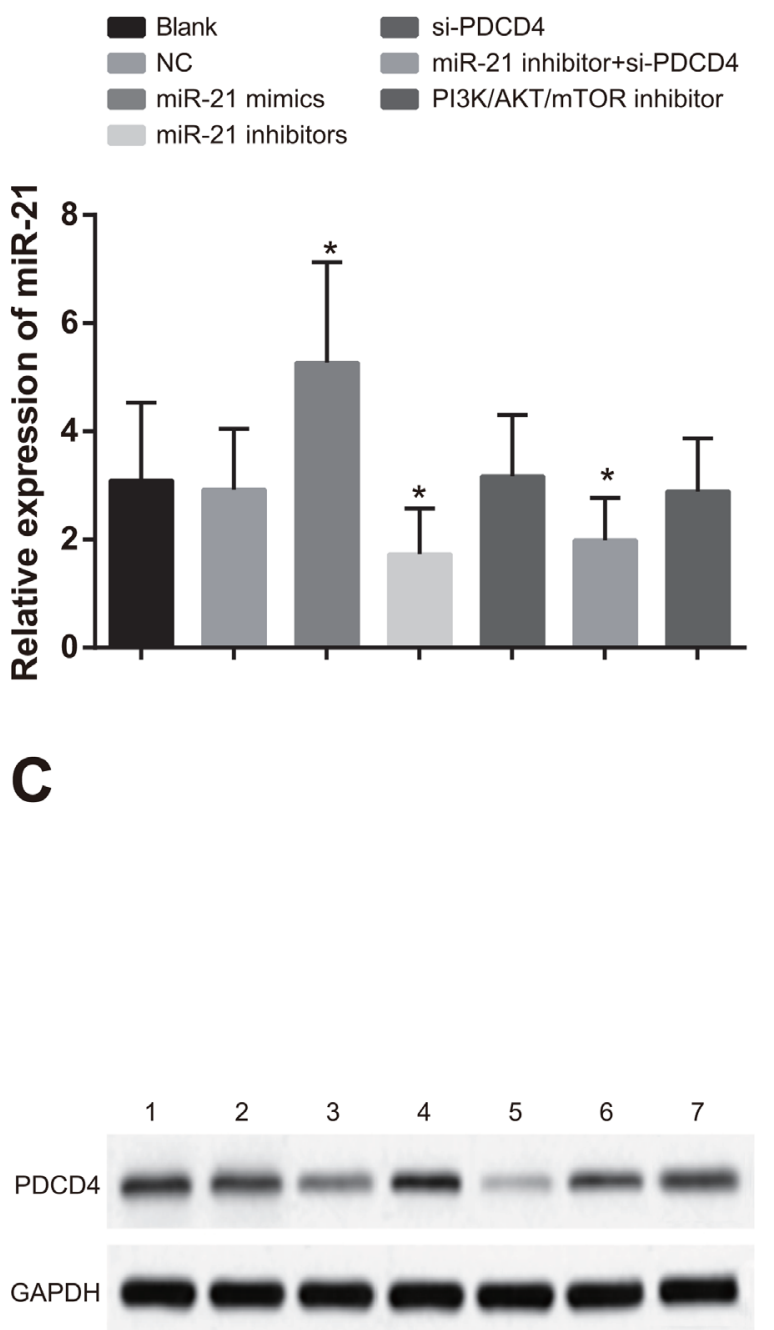

E

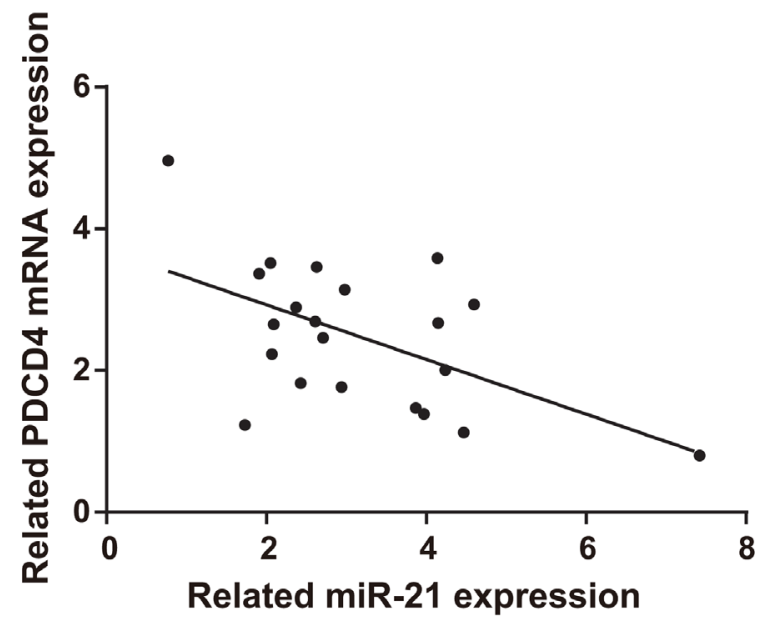

B
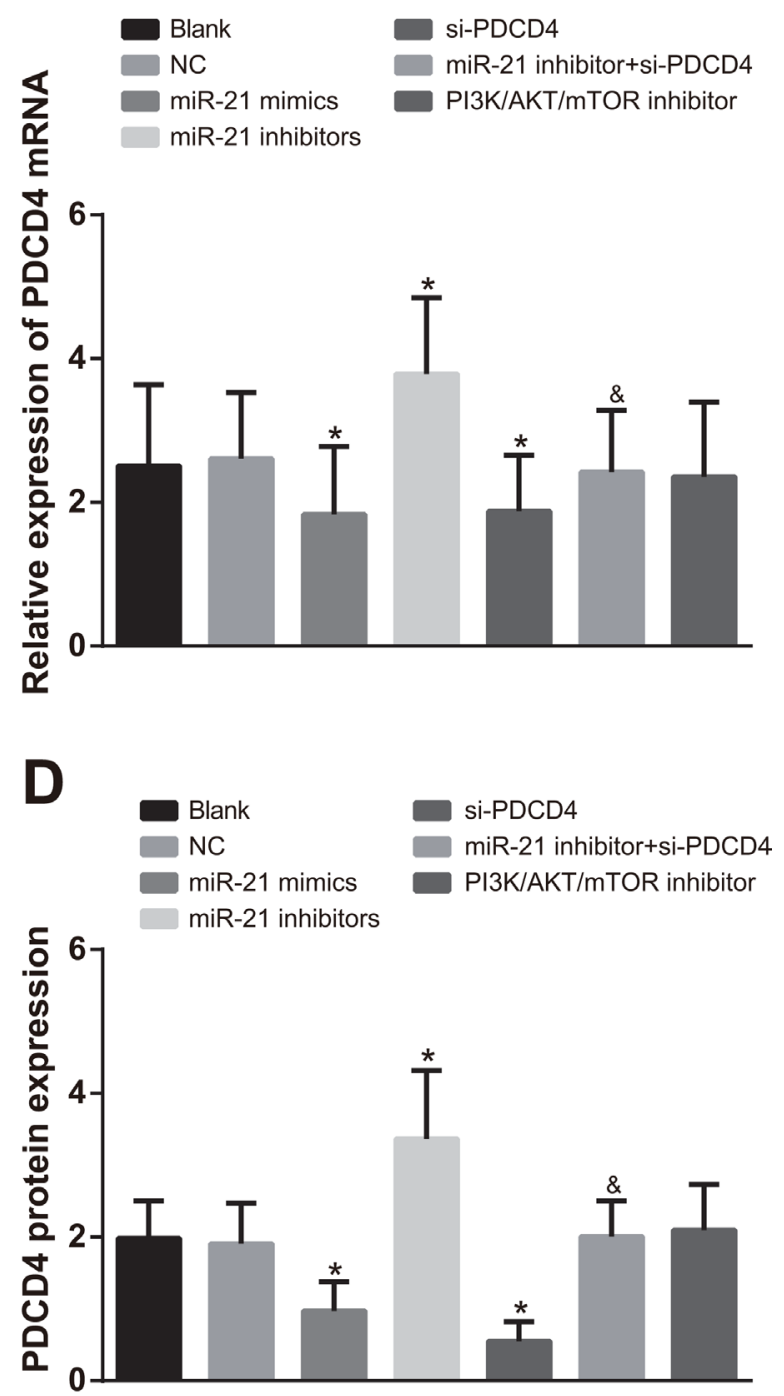

Figure 3: Comparisons of miR-21 expression and mRNA and protein expressions of PDCD4 among different groups in A549 cells. Note: *, compared with the blank group, $P<0.05$; \&, compared with the miR-21 inhibitors group, $P<0.05$; 1 , blank group; 2 , negative control group; 3, miR-21 mimics group; 4, miR-21 inhibitors group; 5, si-PDCD4 group; 6, miR-21 inhibitors + si-PDCD4 group; 7, PI3K/AKT/mTOR inhibitors group; PDCD4, programmed cell death 4; miR-21, microRNA-21. 
A

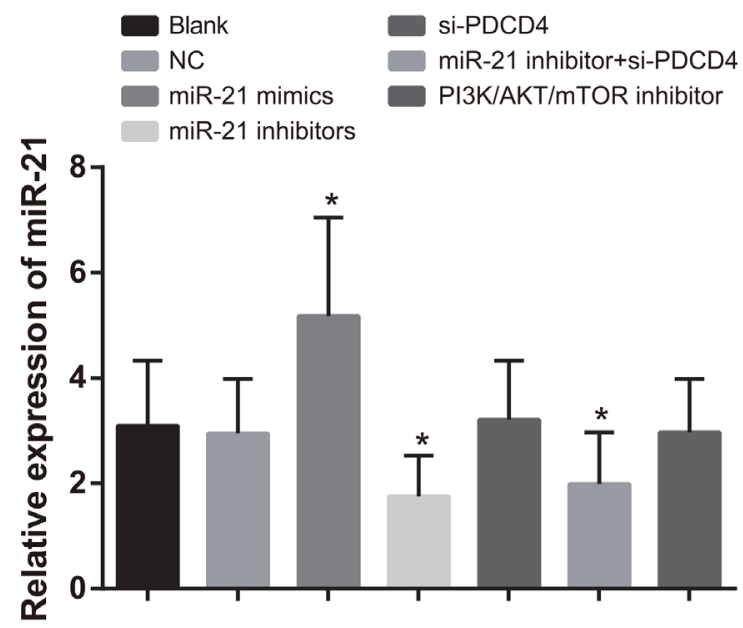

C

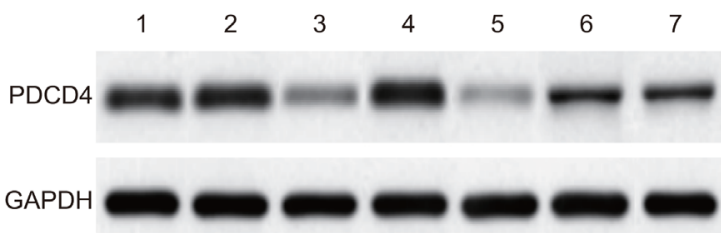

$\mathbf{E}$

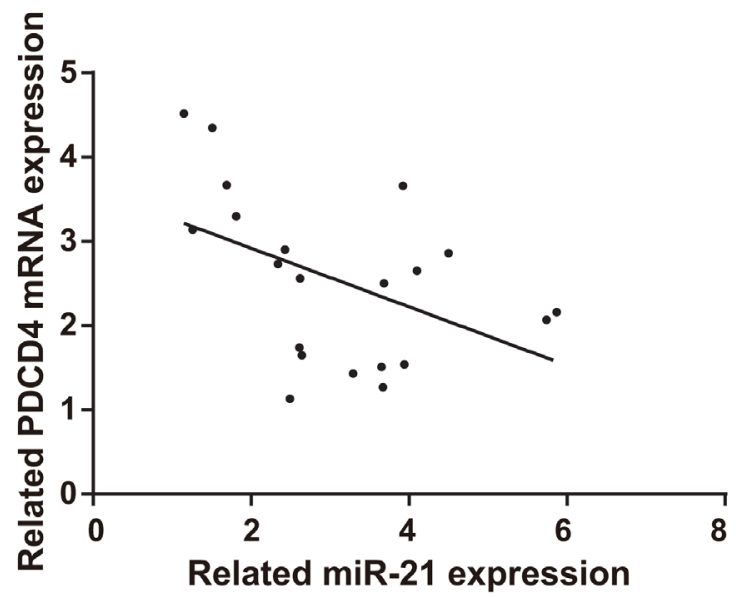

B

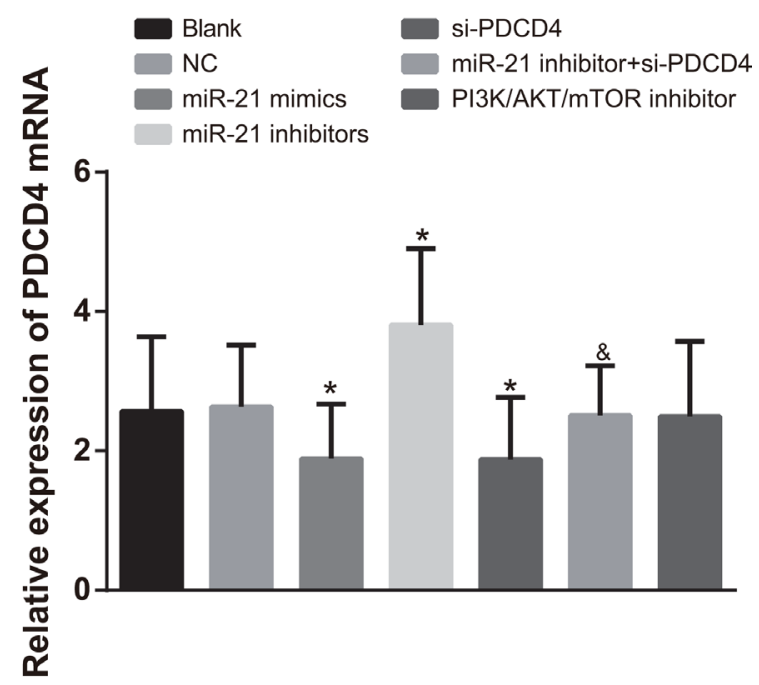

D
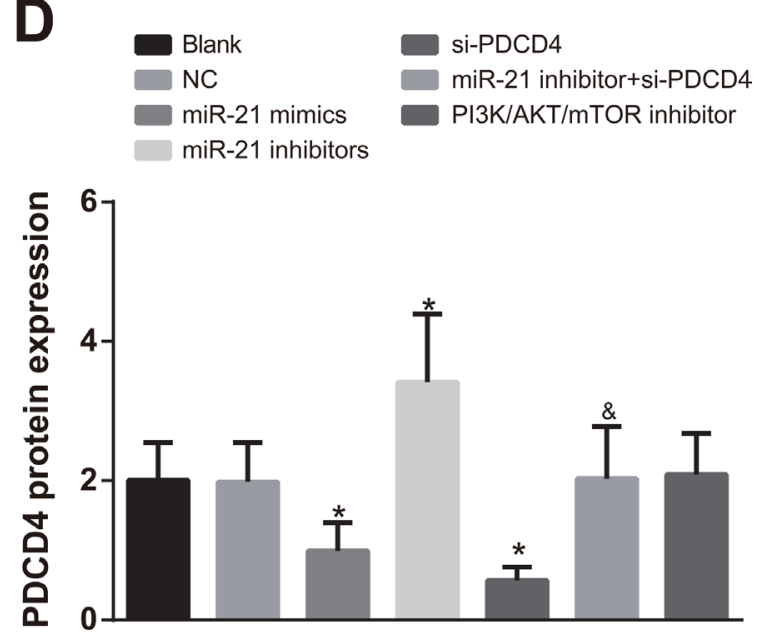

Figure 4: Comparisons of miR-21 expression and mRNA and protein expressions of PDCD4 among different groups in H1299 cells. Note: *, compared with the blank group, $P<0.05$; ${ }^{\star}$, compared with the miR-21 inhibitors group, $P<0.05$; 1 , blank group; 2 , negative control group; 3, miR-21 mimics group; 4, miR-21 inhibitors group; 5, si-PDCD4 group; 6, miR-21 inhibitors + si-PDCD4 group; 7, PI3K/AKT/mTOR inhibitors group; PI3K/AKT/mTOR, phosphatidylinositol-3-kinase/protein kinase B/mammalian target of Rapamycin; PDCD4, programmed cell death 4; miR-21, microRNA-21. 
A

\begin{tabular}{|l|c|c|c|} 
& $\begin{array}{c}\text { Predicted consequential pariring of target region(top) } \\
\text { and miRNA (bottom) }\end{array}$ & $\begin{array}{c}\text { Site } \\
\text { type }\end{array}$ & $\begin{array}{c}\text { Context++ } \\
\text { score }\end{array}$ \\
\hline $\begin{array}{l}\text { Position 242-249 of PDCD4 3' UTR } \\
\text { 5sa-miR-21-5p }\end{array}$ & 8.'. AAGUGGAAUAUCUAAUAAGCUA. . & -0.48 \\
\hline 3' AGUUGUAGUCAGACUAUUCGAU &
\end{tabular}

B

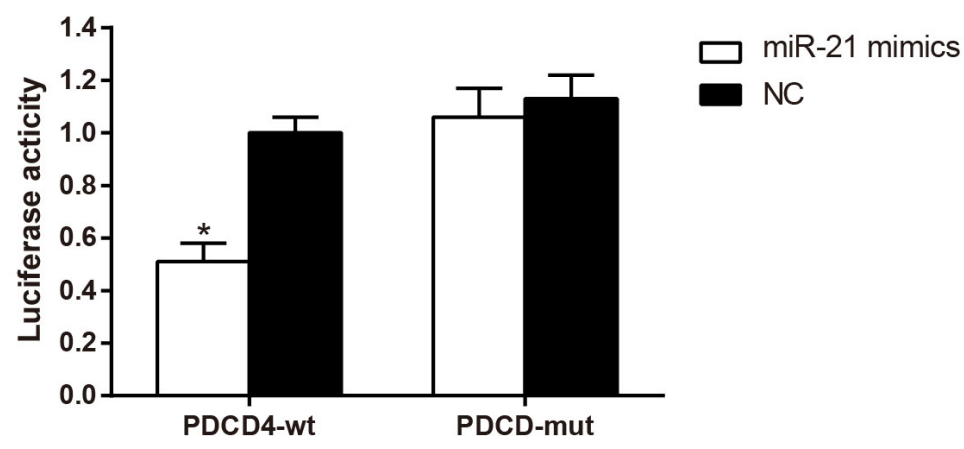

Figure 5: PDCD4 is the target gene of miR-21. Note: A., the binding site of miR-21 with PDCD4 in 3'-UTR as predicted by TargetScan; B., luciferase activity between the miR-21 mimics and NC groups; In cells of the PDCD4 group, transfection with miR-21 decreased the luciferase activity as compared with the NC group; *, compared with the control group, $P<0.05$; PDCD4, programmed cell death 4; miR-21, microRNA-21; NC, negative control.

A

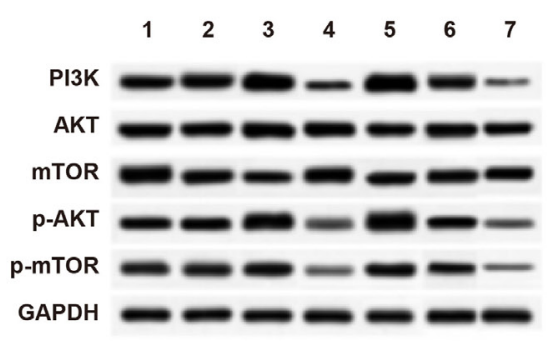

D

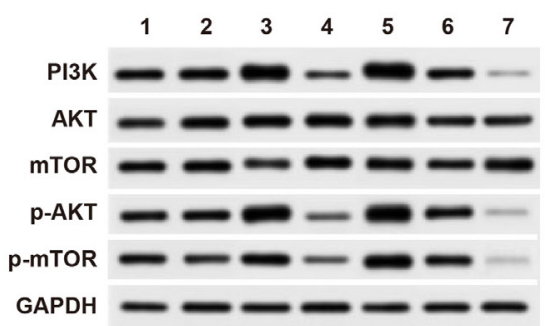

B
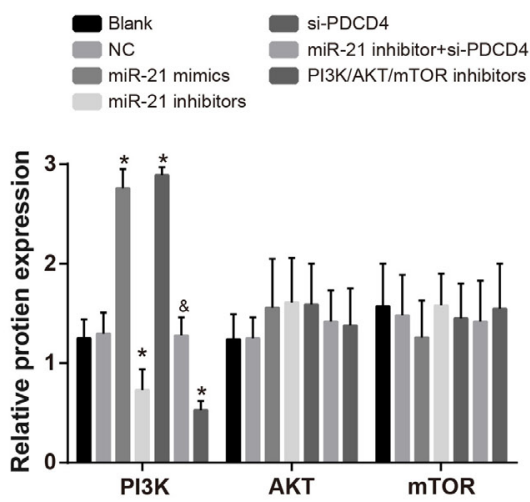

E
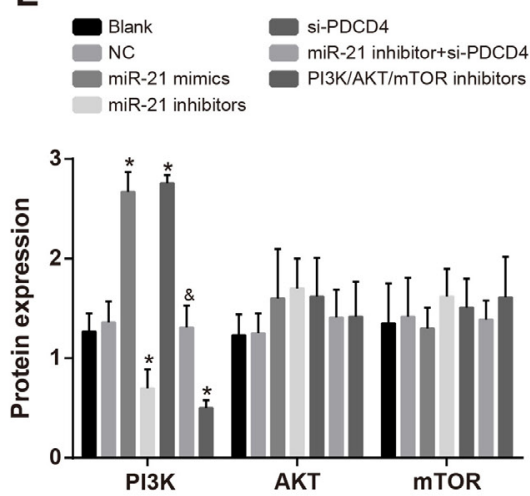

C
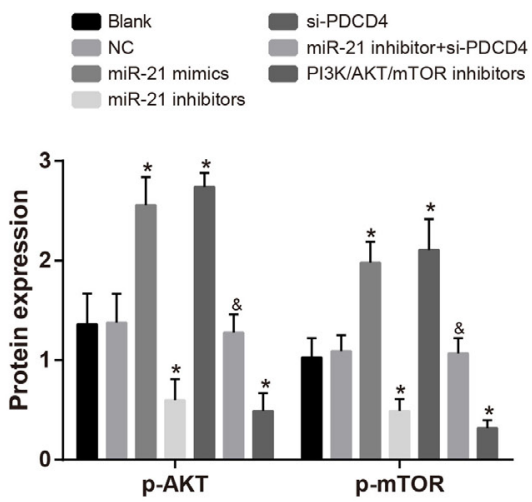

$\mathbf{F}$
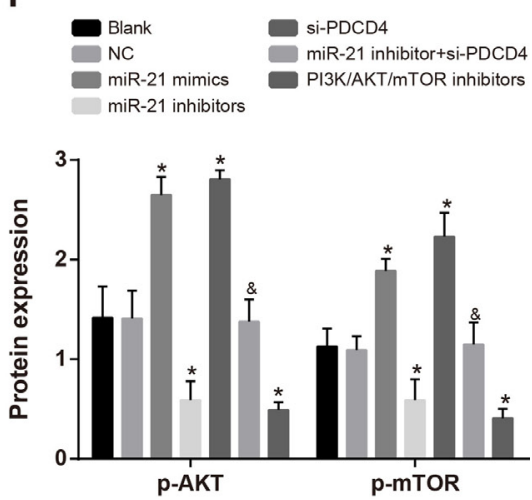

Figure 6: Comparisons of the expressions of PI3K/AKT/mTOR signaling pathway-related proteins among different groups in A549 and H1299 cells after radiotherapy. Note: 1, blank group; 2, negative control group; 3, miR-21 mimics group; 4, miR-21 inhibitors group; 5, si-PDCD4 group; 6, miR-21 inhibitors + si-PDCD4 group; 7. PI3K/AKT/mTOR inhibitors group; *, compared with the blank group, $P<0.05$; ${ }^{\&}$, compared with the miR-21 inhibitors group, $P<0.05$; PI3K/AKT/mTOR, phosphatidylinositol-3-kinase/ protein kinase B/mammalian target of Rapamycin; PDCD4, programmed cell death 4; miR-21, microRNA-21. 
A

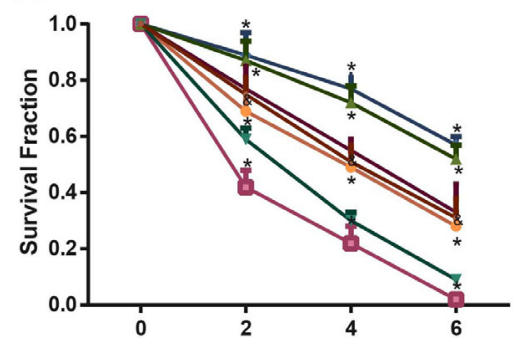

B

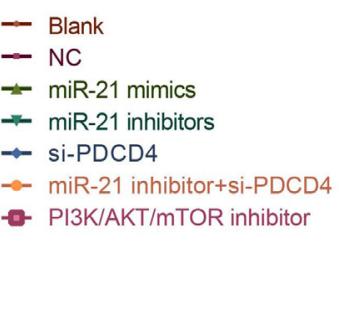

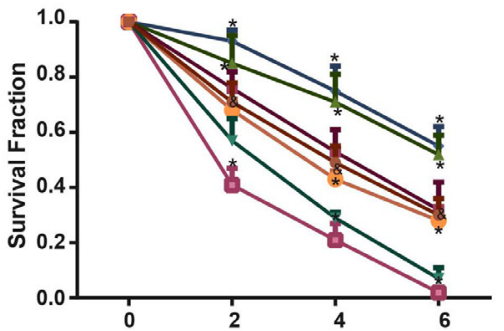

$\sim$ Blank

$=$ NC

\pm miR-21 mimics

$\rightarrow$ miR-21 inhibitors

$\rightarrow$ si-PDCD4

- miR-21 inhibitor+ si-PDCD4

PI3K/AKT/mTOR inhibitor

Figure 7: Comparisons of survival fraction among different groups under different radiation doses. Note: A. The clone formation curve for different groups in A549 cells; B. the clone formation curve for different groups in H1299 cells; *, compared with the blank group, $P<0.05$; ${ }^{\&}$, compared with the miR-21 inhibitors group, $P<0.05$; PDCD4, programmed cell death 4; miR-21, microRNA-21.

A
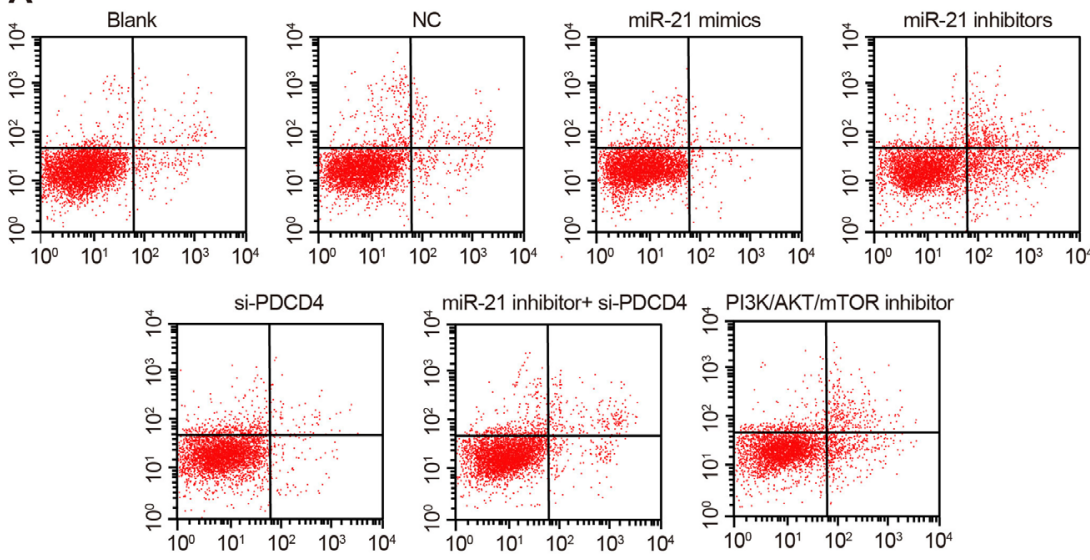

B

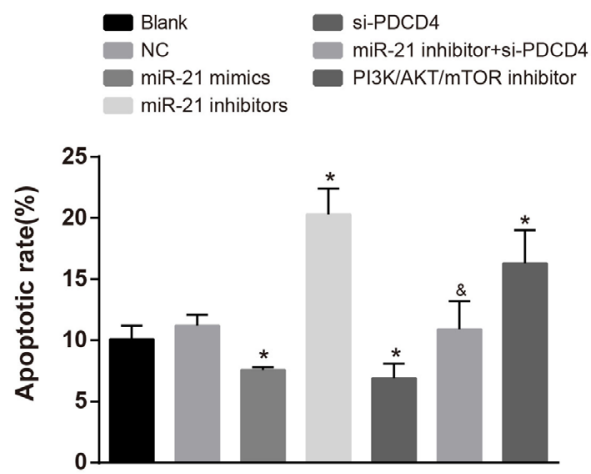

Figure 8: Cell apoptosis among different groups in A549 cells detected by flow cytometry. Note: *, compared with the blank group, $P<0.05$; \&, compared with the miR-21 inhibitors group, $P<0.05$; PDCD4, programmed cell death 4; PDCD4, programmed cell death 4; miR-21, microRNA-21.

A
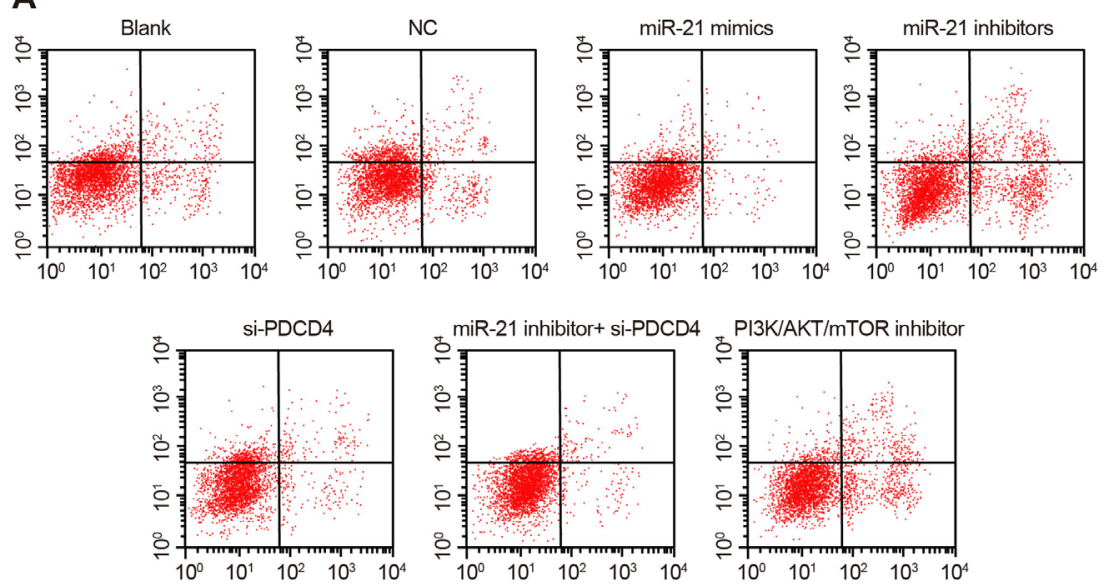

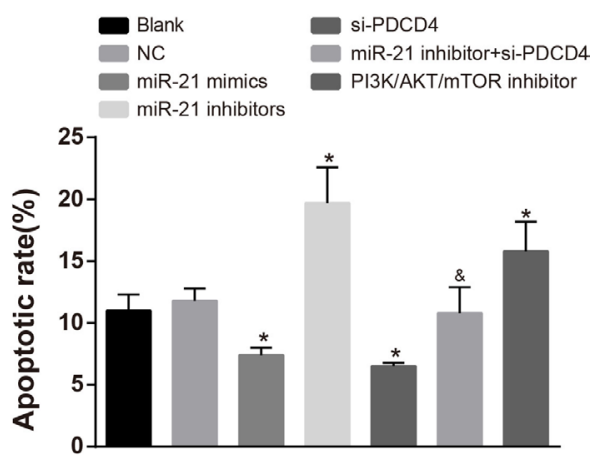

Figure 9: Cell apoptosis among different groups in $\mathbf{H 1 2 9 9}$ cells detected by flow cytometry. Note: *, compared with the blank group, $P<0.05$; ${ }^{*}$, compared with the miR-21 inhibitors group, $P<0.05$; PDCD4, programmed cell death 4; miR-21, microRNA- 21. 
In this study, miR-21 expression was higher in NSCLC tissues than in normal adjacent tissues, and this elevated expression was associated with reduced efficacy of radiotherapy. MiRs are involved in the regulation of cell development, differentiation, proliferation, and apoptosis, and are closely related to the occurrence and development of many diseases [22]. MiR-21 is an oncogenic miR in human malignant tumors, and it is the only miR known to be highly expressed in almost all solid tumors [23, 24]. MiR-21 regulates cell differentiation, proliferation, and apoptosis by regulating target genes, and it is also involved in tumor growth, invasion, and metastasis [25, 26]. The inhibition of miR-21 suppresses proliferation and accelerates apoptosis in cancer cells and renders them more sensitive to chemotherapy [27]. Abnormal miR-21 expression affects the efficacy of various chemotherapy drugs, including gemcitabine, hycamtin, 5-fluorouracil, temozolomide, and taxotere [28, 29]. MiR21 is overexpressed in many solid tumors, including colon cancer, breast cancer, and gastric cancer, and high miR21 expression correlates with disease progression and poor prognosis in patients [30-32]. Tian et al. showed that altered miR-21 expression is related to NSCLC occurrence, development, and survival analysis indicated that miR-21 expression is negatively correlated with NSCLC progression [33]. MiR-21 is also an important miRNA regulating radiosensitivity of human cancer cells $[34,35]$. MiR-21 enhances radioresistance in NSCLC through regulation of phosphatase and tensin homolog deleted on chromosome ten (PTEN) [36].

Here, we found that miR-21 targets PDCD4, and elevated miR-21 expression inhibited PDCD4 expression. Moreover, miR-21 inhibitors can enhance the sensitivity to radiotherapy and reduce cell apoptosis in both A549 and H1299 cells, while those effects can be reversed by the application of si-PDCD4. As a result, miR-21 decreased sensitivity to radiotherapy and enhanced the ability of cancer cells to resist apoptosis, thus reducing the efficacy of radiotherapy. PDCD4, a novel tumor suppressor gene, is involved in apoptosis, and deletions in or reduced expression of PDCD4 have been found in many human malignant tumor tissues and cells [37]. By binding to the translation initiation factor eIF4A (eukaryotic initiation factor-4A), PDCD4 inhibits the translation of proteins and accelerates apoptosis [38]. It also inhibits tumor growth, invasion, and metastasis by activating and regulating the transcription activator protein AP-1 and matrix metalloproteinase 2 (MMP-2) [39, 40]. Zhu et al. also confirmed that miR-21 could modulate PDCD4 expression at the translational and post-transcriptional levels in HepG2 cells, enhance phosphorylation of c-Jun protein, and activate AP-1-dependent transcription of MMP-2 as well as MMP-9, thus promoting migration and invasion of hepatocellular carcinoma cell lines [41]. PDCD4 expression in poorly-differentiated colorectal cancer, gastric cancer, and pancreatic cancer was lower than in highly-differentiated cancers, and deletions in or decreased expression of PDCD4 correlated with poor prognosis [37]. PDCD4 expression was negatively associated with miR-21 levels in gastric cancer [14]. By inhibiting PDCD4, miR21 acts as an anti-apoptotic factor and promotes tumor cell transformation [42]. Asmlgani et al. found that miR-21 inhibits apoptosis and promotes proliferation in colorectal cancer tumor cells by regulating PDCD4 [43]. The miR21 also promotes tumor cell invasion and metastasis in metastatic breast cancer MDA-MB-231 cells by inhibiting the expression of PDCD4 [44]. The study of Chao et al. found that miR-21 knockdown in glioblastoma cells could increase the expression of PDCD4 and hMSH2, which further enhance the radiation sensitivity of cancer cells [35]. Similarly, in our study, miR-21 promoted NSCLC progression by inhibiting PDCD4. To further explore the mechanism of miR-21 decreasing the sensitivity of radiotherapy in NSCLC via targeting PDCD4, the expressions of $\mathrm{PI} 3 \mathrm{~K} / \mathrm{AKT} / \mathrm{mTOR}$ signaling pathway related proteins were detected after radiotherapy. Our results suggested that miR-21 inhibitor can suppress the activation of $\mathrm{PI} 3 \mathrm{~K} / \mathrm{AKT} / \mathrm{mTOR}$ signaling pathway and siPDCD4 can reverse this suppression. As proved that miR21 inhibitor can increase apoptosis rate and enhance the sensitivity of radiotherapy in NSCLC A549 and H1299 cells, it is speculated that miR-21 inhibitor can accelerate cell apoptosis and enhance sensitivity of radiotherapy in NSCLC cells by suppressing PDCD4 and inactivating the $\mathrm{PI} 3 \mathrm{~K} / \mathrm{AKT} / \mathrm{mTOR}$ signaling pathway.

In conclusion, miR-21 could inhibit PDCD4 expression and affect sensitivity to radiotherapy in NSCLC through activating PI3K/AKT/mTOR signaling pathway. In addition, miR-21 inhibitor enhances cell apoptosis in NSCLC and si-PDCD4 could reverse those effects of miR-21. Therefore, miR-21 might be a potential target for enhancing the clinical radiosensitivity in NSCLC in the future. Such research may ultimately lead to novel strategies for the clinical treatment of NSCLC. It should be borne in mind that it is possible that other miRs may also target PDCD4, however, the limitation in time and budget restricted us from conducting any other detection. Therefor further analysis of PDCD4 with other miRs can be served as a future topic in our further experiments.

\section{MATERIALS AND METHODS}

\section{Subjects}

Cancer tissues and adjacent normal tissues $(\geq 5 \mathrm{~cm}$ away from tumor tissue) were collected from 97 NSCLC patients at the First Affiliated Hospital of Liaoning Medical University between February 2013 and August 2015. Fifty-six patients were males and 41 were females, and patient ages ranged from 38 to 81 years with a mean age of $62.73 \pm 9.44$ years. Fifty-three cases were identified as squamous carcinoma and 44 cases as adenocarcinoma 
during pathological examinations. And 60 cases exhibited lymph node metastasis (LNM), while 37 cases did not. TNM stages were determined according to the Union for International Cancer Control standard [45]. There were 14 cases at stage I, 27 cases at stage II, 21 cases at stage III, and 35 cases at stage IV. All patients had normal cardiac and pulmonary function and none received chemotherapy. Tissue samples were quickly transferred to liquid nitrogen and subsequently stored at $-80^{\circ} \mathrm{C}$ until use. This study was approved by the Ethics Committee of the First Affiliated Hospital of Liaoning Medical University. All patients and their families signed informed consent forms.

\section{Treatment regimen}

Before treatment, all patients underwent a computed tomography (CT) scan. Different treatment strategies were developed taking into consideration tumor location, tumor size, and other relevant factors. Patients received three-dimensional conformal radiation therapy after surgery at 2 Gy per treatment 5 times per week for a total radiation dose of about 50 70 Gy over a period of 8 weeks. Radiotherapy efficacy was judged according to the WHO standard [46]. Patients were then categorized into the effective (complete remission [CR] + partial remission $[\mathrm{PR}]$ ) and ineffective (stable disease [SD] + and progression disease [PD]) groups.

\section{Follow-up}

Follow-up visits were conducted through telephone, consultation to outpatient department and reference to medical records, which was terminated in June 2016 after 3 36 months. In total, 6 cases were lost, resulting in a follow-up rate of $93.81 \%$. The PFS of patients were recorded, which commenced from the treatment and ended in NSCLC recurrence, cancer-related death or termination of follow-up.

\section{Terminal deoxynucleotidyl transferase-mediated dUTP nick-end labelling (TUNEL) assay}

After routine dewaxing and dehydration, tissue samples were blocked by hydrogen peroxide and incubated in microwave for $20 \mathrm{~min}$. Terminal Deoxynucleotidyl Transferase (TDT) and biod UTP (Roche Diagnostics $\mathrm{GmbH}$, Mannheim, Germany) were added for incubation at $37^{\circ} \mathrm{C}$ for $1 \mathrm{~h}$. Biotin-labeled horseradish peroxidase was then supplemented for incubation at $37^{\circ} \mathrm{C}$ for $1 \mathrm{~h}$. Samples were then developed with 3,3'-diaminobenzidine tetrahydrochloride (DAB), stained, dehydrated and mounted with neutral resin. Sections with positive expressions of apoptosis cells were considered as positive control. Phosphate buffer solution (PBS) was used as primary antibody for negative control. Apoptotic cells were recognized that were stained into brown in nucleus.
And apoptotic cells in randomized 10 low-magnification fields were selected and calculated for AI.

\section{Cell transfection and grouping}

The A549 and H1299 NSCLC cell lines were provided by the Shanghai Institute of Biochemistry and Cell Biology of the Chinese Academy of Sciences (Shanghai, China). A549 and H1299 cells were seeded on 6 -well plates at a density of $5 \times 10^{4}$ cells $/ \mathrm{mL}$. The cells were cultured in Roswell Park Memorial Institute (RPMI)1640 medium containing 10\% imported fetal bovine serum, $100 \mathrm{U} / \mathrm{mL}$ penicillin, and $100 \mathrm{mg} / \mathrm{L}$ streptomycin. The cells were cultured at $37^{\circ} \mathrm{C}$ in a saturated humidity atmosphere containing 5\% carbon dioxide. During cell passage, cells were trypsinized with $0.125 \%$ trypsin [including $0.1 \%$ ethylenediaminetetraacetic acid (EDTA)]. A549 and H1299 cells in the logarithmic growth phase were collected and assigned into 5 groups: (1) blank group; (2) negative control (NC) group; (3) miR-21 mimics group; (4) miR-21 inhibitors group; (5) si-PDCD4 group; (6) miR-21 inhibitors + si-PDCD4 group; and (7) PI3K/ AKT/mTOR inhibitors group (penicillin as inhibitor). The si-PDCD4, miR-21 mimics, miR-21 inhibitors, and RNA molecule in the NC group were synthesized by Life Technologies Corp. (Grand Island, New York, USA). The primer sequence of miR-21 inhibitor was 5'-GTCGTAT CCAGTGCAGGGTCCGAGGTATTCGCACTGCATAC GACTCAACA -3'. The miR-21 inhibitor was transfected after passage of $24 \mathrm{~h}$, when cells reached $60 \sim 70 \%$ confluence. Following transfection of $24 \mathrm{~h}$, the total RNA was extracted for further experiment.

\section{Quantitative real-time polymerase chain reaction (qRT-PCR)}

The RNeasy Mini Kit (Qiagen, Hilden, Germany) was used according to the manufacturer's protocol to extract total RNA from tumor tissues and adjacent normal tissues. A260/A280 ratio and RNA concentration were measured using a NanoDrop ultraviolet spectrophotometer. Reverse transcription of tissue RNA into cDNA was performed using a reverse transcription kit from Promega (Promega Corp., Madison, Wisconsin, USA). The quantitative fluorescence PCR kit was purchased from Shanghai GenePharma Co., Ltd. (Shanghai, China). The qRT-PCR reaction was carried out using ABI 7500 (Applied Biosystems, Oyster Bay, New York, USA). The reaction volume was $20 \mu \mathrm{L}$, and the reaction conditions were as follows: $3 \mathrm{~min}$ at $95^{\circ} \mathrm{C}$ followed by $12 \mathrm{~s}$ at $95^{\circ} \mathrm{C}$ and $50 \mathrm{~s}$ at $62^{\circ} \mathrm{C}$ for 40 cycles. U6 and $\beta$-actin were used as internal controls for the quantification of miR-21 and PDCD4, respectively. Primers used in the experiments were listed in Table 3 . The $2^{-\Delta \Delta \mathrm{CT}}$ method was used to calculate relative expressions. 
Table 3: Primer sequences for quantitative real-time polymerase chain reaction

\begin{tabular}{ll}
\hline Gene & Primer sequence \\
\hline miR-21 & F: 5'-ACGTTGTGTAGCTTATCAGACTG-3' \\
& R: 5'-AATGGTTGTTCTCCACACTCTC-3' \\
U6 & F: 5'-ATTGGAACGATACAGAGAAGATT-3' \\
& R: 5'-GGAACGCTTCACGAATTTG-3' \\
PDCD4 & F: 5'-ATGTGGAGGAGGTGGATGTG-3' \\
& R: 5'-TGGTGTTAAAGTCTTCTCAAATGC-3' \\
$\beta$-actin & F: 5'-GTGGGGCGCCCCAGGCACCA-3' \\
& R: 5'-CTCCTTAATGTCACGCACGATTT-3' \\
\hline
\end{tabular}

Note: F, forward; R, reverse; miR-21, microRNA-21; PDCD4, programed cell death 4.

\section{Western blotting of PDCD4 protein}

Tissue sample cells and transfected cells were washed with PBS, added to $100 \mu \mathrm{L}$ of cell lysis solution, and incubated at $4^{\circ} \mathrm{C}$ for $30 \mathrm{~min}$. The lysate was centrifuged at $12000 \times \mathrm{g}$ for $10 \mathrm{~min}$, and the protein concentration of the supernatant was measured using the Bradford method. Twelve percent sodium dodecyl sulfate polyacrylamide gel electrophoresis (SDS-PAGE) was performed with a total protein content of $50 \mu \mathrm{g}$ in each lane, and proteins were electro-transferred onto a polyvinylidenefluoride membrane. After incubation with $5 \%$ skim milk in a closed container at room temperature for $1 \mathrm{~h}, 1: 200$ dilution of mouse anti-human PDCD4 antibody and glyceraldehyde-3-phosphate dehydrogenase (GAPDH) monoclonal antibody were added to the mixture followed by incubation overnight at $4^{\circ} \mathrm{C}$. A 1: 10,000 dilution of IRDyeTM800DX-labeled sheep anti-mouse $\mathrm{IgG}$ was added to the mixture after the membrane was washed. Antibodies were purchased from Upstake (USA). After $1 \mathrm{~h}$ of incubation in dark at room temperature, the membrane was fully washed and placed in an Odyssey (Li-cor Biosciences, Lincoln, NE, USA) dual-color infrared laser imaging system for direct image scanning. The integrated optical density of each band was calculated, and relative expression was determined using the ratio of the integrated optical density of the target protein band to that of the GAPDH internal control band.

\section{Dual luciferase reporter gene assay}

Target gene analysis was performed using the TargetScan database in order to determine whether PDCD4 was a direct target of miR-21. The full-length PDCD4 gene 3' UTR region was cloned and amplified. The PCR product was cloned into multiple cloning sites downstream of a luciferase gene in a pmirGLO (Promega Corp., Madison, Wisconsin, USA) vector. The predicted miR-21 binding sites in the target gene were subjected to site-directed mutagenesis, and the Renilla luciferaseexpressing vector PRL-TK (Takara Holdings Inc., Kyoto, Japan) was used as an internal control to adjust for differences in cell numbers and transfection efficiency. Both miR-21 and negative control were transfected into A549 cells with the luciferase vector, and the dual luciferase assay was performed according to the protocols provided by Promega Corp. (Madison, Wisconsin, USA).

\section{Colony formation assay}

Cells in the logarithmic growth phase were washed with PBS twice for cell suspension. After calculated by cell counting method, the cells were diluted into appropriate density and inoculated into 60-mm-diameter plates based on different irradiation doses. Three duplicated wells were set for each irradiation dose. A549 and H1299 cells in the blank group, NC group, miR-21 mimics group, miR-21 inhibitors group, si-PDCD4 group and miR-21 inhibitors + si-PDCD4 group received 0 Gy, 2 Gy, 4 Gy and 6 Gy irradiation, followed by incubation for 10 14 days. During the incubation, the culture medium can be replaced for 1-2 times. In the $14^{\text {th }}$ day of incubation, cells were washed in PBS, fixed in methanol for 20 min and stained with $0.1 \%$ crystal violet for $15 \mathrm{~min}$. After the medium were dried, low-magnification microscope was used to calculate the clone numbers of the colonies that had more than 50 cells. Plating efficiency (PE) and survival fraction (SF) were also calculated based on the following formula: PE $=$ (clone numbers in the blank group/number of inoculated cells in the blank group) $\times 100 \%, \mathrm{SF}=$ clone numbers $/$ (number of inoculated cells $\times \mathrm{PE}$ ).

\section{Flow cytometry}

A549 and H1299 cells in different transfection groups were seeded into 96-well plates in a concentration of $2 \times 10^{4} / \mathrm{mL}$. Each well received $100 \mu \mathrm{L}$ of cells and was cultured for $24 \mathrm{~h}$. The cells received $4 \mathrm{~Gy}$ of X 
ray radiotherapy after attaching to the well surface. After radiotherapy for $48 \mathrm{~h}$, annexin $\mathrm{V}$-fluoroscein isothiocyanate (FITC)/propidium iodide (PI) double staining kit (Keygen biotechnology, Jiangsu, China) was used to detect cell apoptosis rate. Cells were obtained and washed twice with PBS, and then centrifuged for $5 \mathrm{~min}$ at $1900 \times \mathrm{g}$. The supernatant was discarded, and annexin V-FITC/PI staining solution was added into 100 $\mu \mathrm{L}$ of cell suspension, which was mixed and incubated in dark for $15 \mathrm{~min}$ at room temperature. The flow cytometry measurements were performed within $1 \mathrm{~h}$, and the experiment results were analyzed.

\section{Western blotting of PI3K/AKT /mTOR signaling pathway-related proteins}

After the cells in each group were harvested, lysis buffer was added to extract protein and bicinchoninic acid (BCA) method was used to measure the quantification of total protein. Then $25 \mu \mathrm{g}$ protein was added in each well, followed by electrophoresis, transmembrane and block overnight. The membrane was washed with phosphate buffer solution tween-20 (PBST) for 5 times and added with primary antibodies (Cell Signaling Technology Inc., Beverly, MA, USA; PI3K antibody: 1: 1000; AKT antibody: 1: 1000; p-AKT antibody 1: 2000; mTOR antibody 1: 1 000; p-mTOR antibody: 1: 1000 ) at $37^{\circ} \mathrm{C}$ for $1.5 \mathrm{~h}$. After the membrane was washed for 5 times by PBS, horseradish peroxidase labeled secondary antibody was added for incubation at $37^{\circ} \mathrm{C}$ for $1 \mathrm{~h}$. Washed in PBS for 5 times, the membrane was stained, exposed to light, developed with BIORAD GELDOC XR Gel Imaging System and fixation. Quantity One Basic software was applied for analysis of protein bands.

\section{Statistical analysis}

SPSS 19.0 statistical software (SPSS Inc., Chicago, IL, USA) was used for statistical analysis. Count data were displayed as rates or percentages, and comparisons between two groups were conducted using chi-squared tests. Measurement data were displayed as $\bar{x} \pm \mathrm{s}$, and comparisons among multiple groups were conducted using one-way analysis of variance (ANOVA) (homogeneity of variance tests were conducted prior to analysis). The pair-wise comparisons of group means were conducted using LSD $t$-tests. The relationship between expressions of miR-21 and PDCD4 was analyzed using Pearson correlation analysis. Two-tailed $P<0.05$ was considered as statistically significant.

\section{ACKNOWLEDGMENTS}

This study was supported by EGFR/ERK/Livin/ Caspase-3 pathway involves in the apoptosis of human lung adenocarcinoma cell line induced by bufalin (No:
2013022058). We would like to give our sincere thanks to the reviewers for their helpful comments on this article.

\section{CONFLICTS OF INTEREST}

The authors declare no conflicts of interest.

\section{REFERENCES}

1. Ma L, Xie XW, Wang HY, Ma LY, Wen ZG. Clinical Evaluation of Tumor Markers for Diagnosis in Patients with Non-small Cell Lung Cancer in China. Asian Pacific journal of cancer prevention. 2015; 16:4891-4894.

2. Wang Z, Jin $Y$, Ren $H$, Ma X, Wang B, Wang Y. Downregulation of the long non-coding RNA TUSC7 promotes NSCLC cell proliferation and correlates with poor prognosis. Am J Transl Res. 2016; 8:680-687.

3. Park B, Lee G, Kim HK, Choi YS, Zo JI, Shim YM, Kim J. A retrospective comparative analysis of elderly and younger patients undergoing pulmonary resection for stage I nonsmall cell lung cancer. World journal of surgical oncology. 2016; 14:13.

4. Liu M, Zhou C, Zheng J. Cigarette smoking impairs the response of EGFR-TKIs therapy in lung adenocarcinoma patients by promoting EGFR signaling and epithelialmesenchymal transition. American journal of translational research. 2015; 7:2026-2035.

5. Wei R, DeVilbiss FT, Liu W. Genetic Polymorphism, Telomere Biology and Non-Small Lung Cancer Risk. Journal of genetics and genomics. 2015; 42:549-561.

6. Osarogiagbon RU, Lin CC, Smeltzer MP, Jemal A. Prevalence, Prognostic Implications, and Survival Modulators of Incompletely Resected Non-Small Cell Lung Cancer in the U.S. National Cancer Data Base. Journal of thoracic oncology. 2016; 11:e5-e16.

7. Hung JJ, Jeng WJ, Hsu WH, Wu KJ, Chou TY, Hsieh CC, Huang MH, Liu JS, Wu YC. Prognostic factors of postrecurrence survival in completely resected stage I non-small cell lung cancer with distant metastasis. Thorax. 2010; 65:241-245.

8. Mlika M, Laabidi S, Afrit M, Boussen H, El Mezni F. Genomic classification of lung cancer: toward a personalized treatment. La Tunisie medicale. 2015; 93:339-344.

9. Stella GM, Valizia C, Zorzetto M, Inghilleri S, Valentini A, Dore R, Colombo S, Valentino F, Orlandoni G, Morbini P. Unexpected responses to EGFR inhibition in NSCLC. Respiratory medicine case reports. 2015; 16:32-34.

10. Benz F, Roy S, Trautwein C, Roderburg C, Luedde T. Circulating MicroRNAs as Biomarkers for Sepsis. International journal of molecular sciences. 2016; 17.

11. Li T, Li D, Sha J, Sun P, Huang Y. MicroRNA-21 directly targets MARCKS and promotes apoptosis resistance 
and invasion in prostate cancer cells. Biochemical and biophysical research communications. 2009; 383:280-285.

12. Mognato M, Celotti L. MicroRNAs Used in Combination with Anti-Cancer Treatments Can Enhance Therapy Efficacy. Mini reviews in medicinal chemistry. 2015; 15:1052-1062.

13. He Z, Liu Y, Xiao B, Qian X. Mir-25 modulates nsclc cell radio-sensitivity through directly inhibiting btg2 expression. Biochem Biophys Res Commun. 2015; 457:235-241.

14. Cao Z, Yoon JH, Nam SW, Lee JY, Park WS. Pdcd4 expression inversely correlated with mir-21 levels in gastric cancers. J Cancer Res Clin Oncol. 2012; 138:611-619.

15. Wang G, Wang JJ, Tang HM, To SS. Targeting strategies on miRNA-21 and PDCD4 for glioblastoma. Archives of biochemistry and biophysics. 2015; 580:64-74.

16. Halimi M, Parsian H, Asghari SM, Sariri R, Moslemi D, Yeganeh F, Zabihi E. Clinical translation of human microRNA 21 as a potential biomarker for exposure to ionizing radiation. Translational research. 2014; 163:578-584.

17. Jia Z, Wang J, Shi Q, Liu S, Wang W, Tian Y, Lu Q, Chen P, Ma K, Zhou C. SOX6 and PDCD4 enhance cardiomyocyte apoptosis through LPS-induced miR-499 inhibition. Apoptosis. 2016; 21:174-183.

18. Yang Y, Meng H, Peng Q, Yang X, Gan R, Zhao L, Chen Z, Lu J, Meng QH. Downregulation of microRNA-21 expression restrains non-small cell lung cancer cell proliferation and migration through upregulation of programmed cell death 4. Cancer gene therapy. 2015; 22:23-29.

19. Burris HA, 3rd. Overcoming acquired resistance to anticancer therapy: Focus on the pi3k/akt/mtor pathway. Cancer Chemother Pharmacol. 2013; 71:829-842.

20. Zhou Q, Lui VW, Yeo W. Targeting the pi3k/akt/mtor pathway in hepatocellular carcinoma. Future Oncol. 2011; 7:1149-1167.

21. Zhao W, Zhao JJ, Zhang L, Xu QF, Zhao YM, Shi XY, $\mathrm{Xu}$ AG. Serum miR-21 level: a potential diagnostic and prognostic biomarker for non-small cell lung cancer. International journal of clinical and experimental medicine. 2015; 8:14759-14763.

22. Arora A, Singh S, Bhatt AN, Pandey S, Sandhir R, Dwarakanath BS. Interplay Between Metabolism and Oncogenic Process: Role of microRNAs. Translational oncogenomics. 2015; 7:11-27.

23. Lv C, Hao Y, Tu G. MicroRNA-21 promotes proliferation, invasion and suppresses apoptosis in human osteosarcoma line MG63 through PTEN/Akt pathway. Tumour biology. 2016.

24. Effatpanah H, Yadegarazari R, Karami M, Majlesi A, Shabab N, Saidijam M. Expression Analysis of mir-21 and mir-221 in Cancerous Tissues from Iranian Patients with Gastric Cancer. Iranian biomedical journal. 2015; 19:188-193.
25. Li B, Liu F, Peng Y, Zhou Y, Fan W, Yin H, Ai S, Zhang $\mathrm{X}$. Two-stage cyclic enzymatic amplification method for ultrasensitive electrochemical assay of microRNA-21 in the blood serum of gastric cancer patients. Biosensors \& bioelectronics. 2016; 79:307-312.

26. Rafiee-Pour HA, Behpour M, Keshavarz M. A novel labelfree electrochemical miRNA biosensor using methylene blue as redox indicator: application to breast cancer biomarker miRNA-21. Biosensors \& bioelectronics. 2016; 77:202-207.

27. Zhao Y, Zhao L, Ischenko I, Bao Q, Schwarz B, Niess H, Wang Y, Renner A, Mysliwietz J, Jauch KW, Nelson PJ, Ellwart JW, Bruns CJ, Camaj P. Antisense inhibition of microRNA-21 and microRNA-221 in tumor-initiating stem-like cells modulates tumorigenesis, metastasis, and chemotherapy resistance in pancreatic cancer. Targeted oncology. 2015; 10:535-548.

28. Nangia-Makker P, Yu Y, Vasudevan A, Farhana L, Rajendra SG, Levi E, Majumdar AP. Metformin: a potential therapeutic agent for recurrent colon cancer. PloS one. 2014; 9:e84369.

29. Zhang HL, Yang LF, Zhu Y, Yao XD, Zhang SL, Dai B, Zhu YP, Shen YJ, Shi GH, Ye DW. Serum miRNA-21: elevated levels in patients with metastatic hormone-refractory prostate cancer and potential predictive factor for the efficacy of docetaxel-based chemotherapy. The Prostate. 2011; 71:326-331.

30. Feng YH, Wu CL, Shiau AL, Lee JC, Chang JG, Lu PJ, Tung CL, Feng LY, Huang WT, Tsao CJ. MicroRNA21-mediated regulation of Sprouty2 protein expression enhances the cytotoxic effect of 5-fluorouracil and metformin in colon cancer cells. International journal of molecular medicine. 2012; 29:920-926.

31. Fukushima $Y$, Iinuma $H$, Tsukamoto $M$, Matsuda $K$, Hashiguchi Y. Clinical significance of microRNA-21 as a biomarker in each Dukes' stage of colorectal cancer. Oncology reports. 2015; 33:573-582.

32. Wang Y, Zhang Y, Pan C, Ma F, Zhang S. Prediction of poor prognosis in breast cancer patients based on microRNA-21 expression: a meta-analysis. PloS one. 2015; 10:e0118647.

33. Tian L, Shan W, Zhang Y, Lv X, Li X, Wei C. Up-Regulation of miR-21 Expression Predicate Advanced Clinicopathological Features and Poor Prognosis in Patients with Non-Small Cell Lung Cancer. Pathology oncology research. 2016; 22:161-167.

34. Song L, Liu S, Zhang L, Yao H, Gao F, Xu D, Li Q. MiR21 modulates radiosensitivity of cervical cancer through inhibiting autophagy via the PTEN/Akt/HIF-1alpha feedback loop and the Akt-mTOR signaling pathway. Tumour Biol. 2016; 37:12161-12168.

35. Chao TF, Xiong HH, Liu W, Chen Y, Zhang JX. MiR-21 mediates the radiation resistance of glioblastoma cells by regulating PDCD4 and hMSH2. J Huazhong Univ Sci Technolog Med Sci. 2013; 33:525-529. 
36. Liu ZL, Wang H, Liu J, Wang ZX. MicroRNA-21 (miR21) expression promotes growth, metastasis, and chemoor radioresistance in non-small cell lung cancer cells by targeting PTEN. Mol Cell Biochem. 2013; 372:35-45.

37. Ma G, Zhang H, Dong M, Zheng X, Ozaki I, Matsuhashi S, Guo K. Downregulation of programmed cell death 4 (PDCD4) in tumorigenesis and progression of human digestive tract cancers. Tumour biology. 2013; 34:3879-3885.

38. Biyanee A, Singh P, Klempnauer KH. Translation, Pdcd4 and eIF4A. Oncoscience. 2015; 2:731-732. doi: 10.18632/ oncoscience.192.

39. Zhang Z, Zha Y, Hu W, Huang Z, Gao Z, Zang Y, Chen J, Dong L, Zhang J. The autoregulatory feedback loop of microRNA-21/programmed cell death protein 4/activation protein-1 (MiR-21/PDCD4/AP-1) as a driving force for hepatic fibrosis development. The Journal of biological chemistry. 2013; 288:37082-37093.

40. Dikshit B, Irshad K, Madan E, Aggarwal N, Sarkar C, Chandra PS, Gupta DK, Chattopadhyay P, Sinha S, Chosdol $\mathrm{K}$. FAT1 acts as an upstream regulator of oncogenic and inflammatory pathways, via PDCD4, in glioma cells. Oncogene. 2013; 32:3798-3808.
41. Zhu Q, Wang Z, Hu Y, Li J, Li X, Zhou L, Huang Y. miR-21 promotes migration and invasion by the miR21-PDCD4-AP-1 feedback loop in human hepatocellular carcinoma. Oncol Rep. 2012; 27:1660-1668.

42. Chen J, Xu T, Chen $\mathrm{C}$. The critical roles of miR-21 in anti-cancer effects of curcumin. Annals of translational medicine. 2015; 3:330.

43. Asangani IA, Rasheed SA, Nikolova DA, Leupold JH, Colburn NH, Post S, Allgayer H. MicroRNA-21 (miR21) post-transcriptionally downregulates tumor suppressor $\mathrm{Pdcd} 4$ and stimulates invasion, intravasation and metastasis in colorectal cancer. Oncogene. 2008; 27:2128-2136.

44. Teng Y, Manavalan TT, Hu C, Medjakovic S, Jungbauer A, Klinge CM. Endocrine disruptors fludioxonil and fenhexamid stimulate miR-21 expression in breast cancer cells. Toxicological sciences. 2013; 131:71-83.

45. Sobin LH, Gospodarowicz MK, H. WC. International union against cancer (UICC), TNM Classification of malignant tumours. New York: Wiley-Blackwell. 2009; 7th ed.

46. World Health Organization. WHO handbook for reporting results of cancer treatment. Geneva: Offset Publication. 1979. 